\title{
A Study of Cohesion in the Chinese Legal Text: Based on Criminal Procedure Law of the People's Republic of China*
}

\author{
Shifang Li \\ School of Languages and Cultures, Shanghai University of Political Science and Law, China \\ Yifan Wang \\ Shanghai Elearning Investment Consulting Co., LTD, China
}

\begin{abstract}
This study analyzes the textual cohesion of Criminal Procedure Law of the People's Republic of China from the perspective view of Cohesion Theory. According to the data analysis, the study indicates that, in this legal text, the means of cohesion occurs totally 792 times, among which grammatical cohesion takes a large proportion, that is, $\mathbf{8 3 . 9 \%}$, while lexical cohesion takes the ration of $16.1 \%$. In the lexical cohesion, the repetition is used much more frequently, followed by the means of hyponymy/meronymy, synonymy/antonymy and collocation, taking the ratio of $0.8 \%, 0.5 \%$ and $0.4 \%$ respectively. Thus, we can know from the statistics that cohesion is an important feature of the Chinese legal text. It connects the syntactic grammar and the lexicons into together closely in the Chinese legal Articles. Therefore, the paper points out that a proper understanding of the cohesive devices in the Chinese legal text is significant to legal draftsmen and social scientists in the field of language and the law, for they might improve the text quality of their work with it.
\end{abstract}

Index Terms - Cohesion Theory, Chinese legal text, textual features, quantitative analysis

\section{INTRODUCTION}

The present study is concerned with cohesion in the Chinese legal text. The paper adopts Cohesion Theory developed in Cohesion in English (1976) by Michael Alexander Kirkwood Halliday and Ruquaiya Hasan, which is, reference, ellipsis and substitution, conjunction, and lexical cohesion. However, there might be some loophole in the legal texts if something is wrong with the textual cohesion. Possibly it would lead to a potential misrepresentation of the original intention of the lawmakers or misinterpretation by the general public due to a lack of explicit signs of cohesion. Being an essential means to achieve global coherence in a text, cohesion is of vital importance in legislative language which requires extreme accuracy and certainty, as well as avoidance of ambiguity in meaning. In this regard, something should be done to help law drafters in China have a better idea as to how to take care of the textual cohesion in the legislative language, so they would be able to represent more correctly the intentions of the legislative body on the one hand, and achieve a better comprehensibility among the general public on the other.

Legislation is the largest and most powerful source of law and legislative discourse is the most complex and esoteric of all forms of legal discourse (Maley, 1994). Owing to the multi-type of legal language, the thesis merely chooses the Chinese text of Criminal Procedure Law of the People's Republic of China as the research object.

With cohesion theory, the methods of qualitative and quantitative of the study show a statistic of the distribution of the cohesive devices in Criminal Procedure Law of the People's Republic of China. This investigation is a combination of both generality and specialty. It is general in the sense that the textual cohesion is ultimately a universal phenomenon, regardless of the register. It is special because the textual cohesion in the legal register has its own distribution features of cohesive devices.

It should be noted that this study is one of our series of researches on the characteristics of Chinese legal text. Before we have done some relevant research on this Law from the perspectives of theme - rheme structure (Shifang Li \& Yifan Wang, 2020) and thematic of progression (Shifang Li \& Yifan Wang, 2021).

\section{SignificANCE OF THE StUdy}

Basically, cohesion is a universal linguistic phenomenon which is omnipresent, irrespective of any kind of language. However, there are some different ways of the special embodiment in different languages. Cohesion has certain distinctive characteristics in Chinese, besides the common attributes concluded in the related literature. In the legal text, we can observe that the cohesive devices are not of diversity as in any other type of text. It may be due to the following

\footnotetext{
* This research was supported by Research project of Shanghai philosophy and Social Science Foundation for Research and Application of Criminal Judicial Language under the Background of Rule of Law in 2018.
} 
two reasons: on the one hand, there is a tendency for the Chinese language to be more concerned with the consistency in thought rather than the solid mechanisms of cohesion. For example, we can see from the above statistics that there are far less choices in Criminal Procedure Law of the People's Republic of China. On the other hand, there are certainly no exceptions in the legal texts that are very rigid in form, requiring being exact, accurate and unambiguous in meaning. Therefore, the choice of the cohesive devices such as reference, conjunction, ellipsis, collocation and repetition in the Chinese legal text is much simpler and highly limited within a small scale, which can be noted from the statistical table in the above.

The significance of an exploration like the one carried out in the current paper lies in at least two respects: first, it is useful to legal draftsmen in China. Presumably they are already experienced as to the special wording and phrasing of legal texts, it does not necessarily mean that they have all mastered the concept of cohesion in a theoretical sense. The preliminary findings in the paper might be helpful to the Chinese legal draftsmen, on the ground that they could have a better knowledge about cohesion in Chinese legislative articles, which will eventually improve their work.

The study of cohesion in the Chinese legal text is a non-exhaustive and tentative approach, special in two aspects: (1). the linguistic data being dealt with is in Chinese. The most advanced theory of cohesion is done in English, having great influence, while the systematic study of cohesion in Chinese has just started and has a far way to go. This entails a number of jobs in the relatively new field of scholarship; (2). The study of the textual cohesion in the text of a particular register and the legal text is still a new undertaking.

\section{THEORETICAL FRAMEWORK}

\section{A. Cohesion Theory}

The essential prerequisite for conducting the study of cohesion theory is the understanding of the notion of text. The specialized study of text came into being in the 1950s and experienced a substantial development during the 1970s. In Cohesion in English (1976), the concept of cohesion is a semantic one, it refers to relations of meaning that exists within the text and that define it as a text (1976, p.4). Let us cite a classic example:

Wash and core six cooking apples. Put them into a fireproof dish. (Halliday and Hasan, 1976, p3)

Apparently, them in the second sentence refers back to six cooking apples in the first sentence. The anaphoric effect of them offers cohesion to the two sentences (Fakuade \& Vargs, 1992). Therefore, we are able to interpret the meaning of the text because there is cohesion between the two parts of the text. In this sense, we say the two sentences form a meaningful unified whole. On the basis of the notion of text, Halliday and Hasan (1976) continue to put forward anther concept: texture. They suggest that texture is an appropriate term to express the property of 'being a text'. Texture is the major distinction that distinguishes a text from other language units, and it is embodied by the cohesive relations in the text. Looking back at the above example, we can see the cohesive relations between the two items are co-referential, which means the two are identical in meaning.

As a matter of fact, 'text' and 'discourse' are used to refer to the same entity in different regions. They are, in some cases, treated as synonyms, while in others the distinction is taken to distinguish written versus spoken communication. Without text, discourse would not be a linguistic activity (Georgakopoulou and Dionysis, 1997). Therefore, the two terms, 'discourse' and 'text' will not be distinguished in the present paper.

When we refer to the text, we usually use two terms "Cohesion" and "Coherence". In English, "cohesion" and "coherence" derive from the same word root "cohere" which means "glue, tight and consistent and so on". The concept of cohesion in English was firstly proposed by Halliday and Hasan (Halliday \& Hasan, 1976). They propose that "we now come to the most problematical part of lexical cohesion, cohesion that is achieved through the association of lexical items that regularly co-occur" (Halliday \& Hasan, 1976, p.284). Hasan (1984) believes that there is a strong correlation between cohesion and coherence of discourse. Cohesion is not only the connection of the surface clauses in discourse, but also is the means of helping organize discourse through lexicons. Thompson (2004, p.179) considers that "cohesion refers to the linguistic devices by which the speaker can signal the experiential and interpersonal coherence of the text and is thus a textual phenomenon - we can point to features of the text which serve a cohesive function". While Thompson points that "coherence, on the other hand, is in the mind of the writer and reader: it is a mental phenomenon and cannot be identified or quantified in the same way as cohesion" (2004, p.179). Although "cohesion" and "coherent" are two different concepts, the two are interlinked in most of cases. In general, the discourse using the source of linguistic cohesion is usually coherent. Cohesion is a critical linguistic resource to express the coherent meaning.

Cohesion is a semantic concept as well as discourse. Halliday (1994) and Halliday\& Matthiessen (2004) classify it into "Grammatical Cohesion" and "Lexical Cohesion". "Grammatical Cohesion" falls into four types: reference, ellipsis, substitution and conjunction. "Lexical Cohesion" also falls into four types: repetition, synonymy/antonymy, hyponymy/meronymy and collocation. We will detailly discuss them in the following sections.

\section{B. Grammatical Cohesion}

Reference is one type of grammatical repetition in terms of systemic functional linguistics. Thompson holds that "Reference is the set of grammatical resources that allow the speaker to indicate whether something is being repeated from somewhere earlier in the text (i.e. we have already been told about it), or whether it has not yet appeared in the 
text (i.e. it is new to us)" (2004, p.180). Generally speaking, reference includes "personal reference", "demonstrative reference" and "comparative reference". Actually, some scholars believe that there should be another two types due to the peculiarities of legal discourse: "category reference" and "reference of legal terminology".

Reference refers to the semantic relation in which the addressee is enabled to identify certain entity by using a word or words. Reference can be sub-categorized as exophora and endophora which can be sub-categorized further as anaphora and cataphora. Exophoric reference refers to an item whose referent is retrievable in the context of situation. Exophoric relation is a means of connecting 'outwards' to some entities in the situation. Endophoric reference refers to an item whose referent can be retrievable within the text. It falls into two types: anaphoric relations which are the reference backward, and cataphoric relations which are the reference forward. However, there are three types of reference: personal reference, demonstrative reference and comparative reference. While the pronominal reference, which often extends over long stretches without the full referent being explicitly specified or needing to be repeated, reflects the constant focus on the same topic, and the fact that both interactants expect the other to co-operate in accepting a fair degree of inexplicitness (Thompson, 2004, p.242). The following table shows the personal reference items:

TABLE 1

PERSONAL REFERENCE ITEMS

\begin{tabular}{|l|l|l|l|l|}
\hline Personals & Function & Determinative & Possessive & Deictic \\
\hline Class & Masculine & he/him & his & his \\
\cline { 2 - 5 } Singular & Feminine & she/her & hers & her \\
\cline { 2 - 5 } & Neuter & it & its & its \\
\hline Plural & & they/them & theirs & their \\
\hline
\end{tabular}

Demonstrative reference is necessarily "a form of verbal". Speakers identify or point out the referent by make it located on the level of proximity. The demonstrative pronouns can be summarized in the following table:

TABLE 2

DEMONSTRATIVE REFERENCE ITEMS

\begin{tabular}{|c|c|c|c|c|}
\hline \multicolumn{5}{|c|}{ Demonstratives } \\
\hline Class & Function & Head & Deictic & Adjunct \\
\hline \multirow[t]{2}{*}{ Specific } & Near & this/these & this/these & here (now) \\
\hline & Remote & that/those & that/those & there (then) \\
\hline \multicolumn{2}{|c|}{ Non-specific } & it & The & \\
\hline
\end{tabular}

"Whereas personals and demonstratives, when used anaphorically, set up a relation of reference, whereby the same entity is referred to over again, comparatives set up a relation of contrast. In comparative reference, the reference item still signals 'you know which'; not because the same entity is being referred to over again but rather because there is a frame of reference-something by reference to which I am now talking about is the same or different, like or unlike, equal or unequal more or less"( Halliday \& Matthiessen, 2004, p.560). Comparative reference can be summarized as the following table:

TABLE 3

COMPARATIVE REFERENCE ITEMS

\begin{tabular}{|c|c|c|c|c|}
\hline \multicolumn{5}{|c|}{ Comparatives } \\
\hline Class & Function & Deictic/numerative & Epithet & Adjunct/Submodifier \\
\hline \multirow[t]{3}{*}{ General } & Identify & $\begin{array}{ll}\text { same, } & \text { equal, } \\
\text { identical... } & \\
\end{array}$ & & Identically, (just) as... \\
\hline & Similarity & similar, additional... & such & $\begin{array}{ll}\text { so, } & \text { likewise, } \\
\text { similarly... } & \end{array}$ \\
\hline & Difference & other, different... & & $\begin{array}{ll}\text { otherwise, } & \text { else, } \\
\text { differently... } & \end{array}$ \\
\hline \multicolumn{2}{|l|}{ Particular } & $\begin{array}{l}\text { more, } \\
\text { further...;so, as... }+ \\
\text { numeral }\end{array}$ & $\begin{array}{l}\text { bigger...;so, as, more, } \\
\text { less... + adjective }\end{array}$ & $\begin{array}{l}\text { Better...;so, as, more, } \\
\text { less... + adverb }\end{array}$ \\
\hline
\end{tabular}

Category reference is a legal category occurs in the legal text with high frequency. It refers to that the parallel words in the preceding words and the last category word belong to the possessive relation, that is, the last word (the so called "general word") can sum up the meaning of the previous words.

Reference of legal terminology also has high frequency used in the legal text. It means that there is certain connection among the parallel words from the legal sense. These words do not constitute the "category reference" but achieve the similar legal effect.

People usually choose to omit some components in the clause when there are unnecessary words or lengthy that is repeated. The missing part can be found in the previous discourse. It is a grammatical means to avoid duplication, highlight new information and make the text compact. The device does not have an effect on the hearer's understanding but different from reference, ellipsis only occur in adjacent clauses. Halliday and Matthiessen hold hat "ellipsis sets up a 
relationship that is not semantic but lexicogrammatical - a relationship in the wording rather than directly in the meaning"(2004, p.562).

Substitution refers to use an alternative word to replace a certain component. It is a grammatical issue, indicating the relation among words. It serves as a place-holding device, implying where something is omitted and showing its grammatical function.

Actually, ellipsis and substitution are variants of the same type of cohesive relation. However, ellipsis and substitution seem to follow and refer to the same principles. But there still exists two main differences. One is that the relation of coherent items changes from co-reference into congener and from a lexical item into structural item. The second is that the two are substituted or omitted when the item and the structure is repeated. From the perspective of meaning, there is always a presupposition to show that the item or the structure appears in the previous discourse and is repeated here when we use the device of ellipsis. From the view of structure, it always leaves a vacancy for the hearer to fill. Therefore, ellipsis and substitution are the same. Sometimes ellipsis is called "zero substitution" (Halliday \& Hasan, 1976). In other words, in some cases, there are no absolute principle restrictions whether the speaker uses substitution or ellipsis.

Some possible meanings within the category of extension, enhancement and elaboration are expressed by the cohesive device of conjunction using some conjunctive adjuncts. Speakers usually use a number of conjunctive items consciously either in spoken language or written language so as to make their wording heard logically. Conjunction plays an essential part in how to combine clauses together in order to make the text coherent. There are many types of conjunction. We will take about the six main types, namely the enumerative conjunction (such as "firstly", "to begin with", "then", "in the end"), the reinforcing conjunction (such as "moreover", "also", "furthermore", "in addition"), the apposition (such as "for example", "in other words", "that is to say"), the result (such as "as a result", "hence", "therefore", "consequently", "hence"), the concessive conjunction (such as "though", "yet", "besides", "anyhow", "however") and the temporal transition (such as "meanwhile", "meantime").

As the above introduces, conjunction is a tool which reflects the logic relation of discourse by the connecting components such as the transitional words. What's more, within a clause or among clauses, there are usually conjunctive elements linking clauses together to show the logico-semantic relation and the inter-dependency relation among clauses (Halliday, 1994). If no conjunction, there must be punctuation marks to indicate the logical relation such as a colon indicating the further explanation and detailed content, a semicolon indicating a parallel relationship, a comma indicating the compact parallel relation.

In a word, the conjunctive subdivision is an essential means to build up the relations among clauses. They play an important role in helping construct coherence in text.

\section{Lexical Cohesion}

There is no possibility for people to turn their topics from time to time. They are willing to focus on their point of topic by one systematic line. So as to keep the discourse as a whole and stress on the main idea, they usually use the key words repeatedly. They choose words to guarantee the continuity of the discourse. However there is no need for the repetition. People can reiterate the word with its synonym, superordinate or general word. We mainly talk about four types of lexical cohesion here: repetition, synonymy/antonymy, hyponymy/meronymy, and collocation. The "Repetition" here we said refers to the repetition of vocabulary. The Chinese scholar, Zhu yongsheng (2001) hold the view that the repetition refers to a certain word (usually the key word) appears in the same discourse repeatedly. Using the repeated words can not only prominent the theme and the main idea, but also play the role of being the link of discourse. It can make the sense of the discourse coherent. There are three forms of repetition: (1) the repeated words consistent with the form; (2) the repeated words having differences in the singular and plural forms; (3) the repeated words derived from the same root. Synonyms and antonyms can also play a bridging role of cohesion. The synonymy/antonymy here we said is a broad concept, not restricted with the part of speech. The hyponymy/meronymy is contained in the "superordinate". The superordinate refers to the word class while the hyponym refers to the word species. The meaning of superordinate is general and abstract while that of hyponym is concrete. The type "collocation" refers to a coherent independent of any type of semantic relationship. It is a special link among words which may occur in the same discourse at the same time.

In conclusion, we need to link words and clauses together so as to create a discourse and we need to construct the discourse by the same systematic line. Cohesion including reference, ellipsis, conjunction and lexical cohesion makes it possible for us to get such a coherent discourse. It is helpful for us to make analysis on the process of cohesion. It helps us a lot to get a better understanding of our reading and it plays an essential role in our writing as well. It could be impossible for us to produce nonsense passages deviating from the topic. As Thompson said, "it is a mental phenomenon and can not be identified or quantified in the same way as cohesion" (Thompson: 2004, p179). Cohesion is the main means to show coherence in any discourse. Thus, it is essential for us to adopt the advantages of the cohesive devices in creating a legal text.

\section{RESULTS AND DiscusSiON}

Cohesion is a kind of semantic concept as well as the term of discourse. It refers to the semantic connection among 
the linguistic components in the discourse, or in other words, the relationship between a component and another one which can make explanation for each other in the discourse. When a component depends on the interpretation of another component in the discourse, the relation of cohesion is produced. Cohesion is different from other concepts such as morpheme, word, phrase, clause, sentence and so on. The former belongs to the semantic concept while the latter belongs to the grammatical concept. The latter is the concrete manifestation of the former. As is elaborated in section II, Halliday has divided cohesion into grammatical cohesion and lexical cohesion. Grammatical cohesion falls into the following four types: reference, ellipsis, substitution and conjunction. Lexical cohesion falls into four types as well: repetition, synonymy/antonymy, hyponymy/meronymy and collocation. In the following part, we will take it about in the legal text.

\section{第二十九条 审判人员、检察人员、侦查人员有 \\ 下列情形之一的, 应当自行回避, 当事人及其 \\ 法定代理人也有权要求他们回避:}

(《中华人民共和国刑事诉讼法》第一编第三章第二十九条)

English version:

(https://www.lawinfochina.com/display.aspx?id=29202\&lib=law )

"Article 29 Under any of the following circumstances, a judge, prosecutor, or investigator shall voluntarily disqualify himself or herself, and a party or his or her legal representative shall have the right to request the disqualification thereof: ..."

(https://www.lawinfochina.com/display.aspx?id=29202\&lib=law)

In Article 29 there are two personal pronouns: "their" and "his". The former refers to the parties mentioned in the previous and the latter refers to any member of the judicial, procuratorial or investigatory personnel mentioned in the previous. That is the "reference" in cohesion. It also uses the means of repetition: "withdraw" and "withdrawal", which are the different forms of the same root word. Besides, there is an obviously mark of conjunction: "and" which connects two clauses naturally. Sometimes the means of conjunction and ellipsis are used together, see the following Article.

第二十七条 上级人民法院可以指定下级人民

法院审判管辖不明的案件, 也可以指定下级

人民法院将案件移送其他人民法院审判。

(《中华人民共和国刑事诉讼法》第一编第二章第二十七条) ( https://www.lawinfochina.com/display.aspx?id=29202\&lib=law)

English version:

"Article 27 A people's court at a higher level may designate that a people's court at a lower level try a case over which jurisdiction is unclear or designate that a people's court at a lower level transfer a case to another people's court for trial."

( https://www.lawinfochina.com/display.aspx?id=29202\&lib=law)

The "and" appearing in Article 27 connects two clauses. However, the second clause following after "and" omits the subject "a People's Court at a higher level". In such condition where the clauses connected by the conjunctions have the same subject, there occurs "ellipsis" to avoid the unnecessary repetition in the sense of the phrases. In fact, there is another means to achieve such effect besides ellipsis, that is, substitution.

第十二条 未经人民法院依法判决，对任何人都不得确定有罪。

(《中华人民共和国刑事诉讼法》第一编第一章第十二条)

( https://www.lawinfochina.com/display.aspx?id=29202\&lib=law)

English version:

"Article 12 No person shall be found guilty without being judged so by a people's court in accordance with the law."

( https://www.lawinfochina.com/display.aspx?id=29202\&lib=law)

Here it uses "such" to substitute the action of sentencing to be guilty in order to avoid the redundancy and complicated repetition. Through the analysis we find it that there are types of hyponymy/meronymy, synonymy/antonymy and collocation used in "Criminal Procedure Law of the People's Republic of China".

第八十三条 公安机关在异地执行拘留、逮捕的时

候, 应当通知被拘留、逮捕人所在地的公安机关,

被拘留、逮捕人所在地的公安机关应当予以配合。

(《中华人民共和国刑事诉讼法》第一编第六章第八十三条)

( https://www.lawinfochina.com/display.aspx?id=29202\&lib=law)

English version:

"Article 83 Where a public security authority executes detention or arrest of a person in a different place, it shall notify the public security authority at the place of residence of the detainee or arrestee, and the public security authority at the place of residence of the detainee or arrestee shall provide cooperation."

( https://www.lawinfochina.com/display.aspx?id=29202\&lib=law)

The definition of collocation given by Halliday and Hasan (1976) is very wide, including the items among clauses or 
the relationship of these items among paragraphs.

In general, any two lexical items having similar patterns of collocation - that is tending to appear in similar context-will generate a cohesive forces if they occur in adjacent sentences (Halliday \& Hasan, 1976, p.286).

In the above Article 83, there are two items "arrest" and "detain". There is certain necessary objective link between the two. In the procedure, when a criminal suspect is arrested, the following step is usually the criminal detention, that is, to keep him in custody for certain days. The application of collocation makes it much more accurate and completed. Let us see another article selected from the Law.

第三十一条 审判人员、检察人员、侦查人员的回

避，应当分别由院长、检察长、公安机关负责人

决定; 院长的回避，由本院审判委员会决定； ......

(《中华人民共和国刑事诉讼法》第一编第二章第三十一条) (https://www.lawinfochina.com/display.aspx?id=29202\&lib=law )

English version:

"Article 31 The disqualification of a judge, prosecutor, or investigator shall be decided respectively by the president of a people's court, the president of a people's procuratorate, and the chief of a public security authority; the disqualification of the president of a people's court shall be decided by the judicial committee of the court; ..."

(https://www.lawinfochina.com/display.aspx?id=29202\&lib=law )

Here "judge", "procurator", "investigator", "president of the court" and "the chief procurator" occurring in the Article 31, all belong to the category of the law enforcement officials. Therefore they are the meronymys of the same hyponymys. By using the meronymys, it achieves an effect of coherent in the meaning.

第四十三条 辩护律师经证人或者其他有关单位

和个人同意，可以向他们收集与本案有关的材料，

也可以申请人民检察院、人民法院收集、调取证

据，或者申请人民法院通知证人出庭作证。

(《中华人民共和国刑事诉讼法》第一编第四章第四十三条) (https://www.lawinfochina.com/display.aspx?id=29202\&lib=law )

English version:

"Article 43 A defense lawyer may gather information regarding a case from a witness or any other relevant entity or individual with the consent thereof, and may also apply to the people's procuratorate or people's court for gathering or submission of evidence or apply to the people's court for notifying a witness to testify before court. ..."

(https://www.lawinfochina.com/display.aspx?id=29202\&lib=law )

In Article 43 the items of "collect information" and "obtaining of evidence" refer to the same activity in fact, that is, to select some relative messages that are beneficial to the case. Therefore, the relationship between the two items belongs to the type of synonymy/antonymy in cohesion. After the statistical analysis we get the following table of the application of cohesion theory in the Law. And we find the distribution of cohesion in the Law.

TABLE 4

DISTRIBUTION OF COHESIVE DEVICES IN THE LAW

\begin{tabular}{|c|c|c|c|c|c|}
\hline \multirow{9}{*}{ Cohesion } & number & & fication & number & ratio \\
\hline & \multirow{8}{*}{792} & \multirow{4}{*}{$\begin{array}{c}\text { Grammatical } \\
\text { cohesion }\end{array}$} & Reference & 369 & $46.6 \%$ \\
\hline & & & Ellipsis & 47 & $5.9 \%$ \\
\hline & & & Substitution & 118 & $14.9 \%$ \\
\hline & & & Conjunction & 131 & $16.5 \%$ \\
\hline & & \multirow{4}{*}{ Lexical cohesion } & Repetition & 114 & $14.4 \%$ \\
\hline & & & Synonymy/antonymy & 4 & $0.5 \%$ \\
\hline & & & Hyponymy/meronymy & 6 & $0.8 \%$ \\
\hline & & & Collocation & 3 & $0.4 \%$ \\
\hline
\end{tabular}

We can see that, from the table, in the discourse of Criminal Procedure Law of the People's Republic of China, the means of cohesion occurs totally 792 times, among which grammatical cohesion takes a large proportion, that is, 83.9\%, while lexical cohesion takes the ration of $16.1 \%$. Specifically speaking, the proportion of means of reference is $46.6 \%$, the one of ellipsis is $5.9 \%$, the one of substitution is $14.9 \%$ and the one of conjunction is $16.5 \%$. In the lexical cohesion, the repetition is used much more frequently, followed by the means of hyponymy/meronymy, synonymy/antonymy and collocation, taking the ratio of $0.8 \%, 0.5 \%$ and $0.4 \%$ respectively. Thus, we can know that cohesion is an important feature of the legal text. It connects the syntactic grammar and the lexicons into together closely in the legal Article. The linguistic phenomenon may lies in the surface structure of the text, or among the paragraphs and clauses, or among the components of the same clause. The phenomenon of cohesion can be found here and there through making an analysis on the Criminal Procedure Law of the People's Republic of China. The linguistic components can be made into an organic whole with the devices of cohesion. Therefore, cohesion is usually considered to be the "physical network" of the text.

From the perspective of the text production process, cohesion is the prerequisite condition to make different clauses 
into a whole, while from the perspective of the text which has been generated already, as is said in the above, cohesion is the means to reflect the important features of text. In the Law, cohesion makes the objective reference more specific, clear and tight to introduce the means of reference frequently in order to make the legal language more precise and accurate.

Conjunction is a kind of means to reflect the logical relationship of the discourse by using the components of conjunction. In the Law, the conjunctions of the logical relationship are mostly parallel and transition. The use of conjunction makes the logical relationship of the legal text structured and clear so as to reflect the rigidness and the compulsion of the legislative language.

In section II, we have mentioned that the substitution is the means which uses the alternative words to replace certain compositions while the ellipsis refers to omit certain component of the text. Therefore from this kind of view, the purpose of the substitution and the ellipsis is all to avoid the unnecessary repetition so as to highlight the new information, compacting the meaning of the discourse from both the grammatical structure and the sense. It fully embodies the elites of legal language, and reflects the accuracy of the legal text to use the two cohesive devices flexibly.

Next let us see the application of lexical cohesion in the Law. The repetition we mentioned here refers to the lexical repetition, that is, certain words (usually the key words) appear in the same text repeatedly. We know that to avoid the lexical repetition is an important rhetorical device such as the above-mentioned substitution and ellipsis, of which the goal is to make the text clearer and more concise. However, in the text of Criminal Procedure Law of the People's Republic of China, to use the lexical repetition appropriately can not only highlight the theme and the central idea, but also play the role of linking text together closely. Thus it achieves an effect that makes the text convergent and coherent, which reflects the mandatory compulsion and the authority of the Law. The legislative language has always been known for its rigidness, accuracy and meticulousness. Therefore, in the legal text of Criminal Procedure Law of the People's Republic of China there is application of synonymy/antonymy, that is, to use multiple words to represent the same meaning of one word. However, lexicons can not have the same meaning completely. Most of the legislative lexicons belong to the cognitive synonyms. There are differences more or less in other concepts or sense except the similarity of the ideational meanings. The Criminal Procedure Law of the People's Republic of China is a procedural law which defines many details of the enforcement process. So although the synonymous appears in the Law, its proportion is not so large. Similarly, the devices of hyponymy/meronymy and collocation take a very small proportion in it. As we know the lexicon is the main carrier of the meaning of language and cohesion is the tool to connect these meaningful words in order to express coherent sense and thus to deepen people's understanding of the structure and function of the text.

\section{CONCLUSION}

In summary, this paper takes examples to analyze the textual features of Criminal Procedure Law of the People's Republic of China by using Cohesion Theory. We can know from the statistics that cohesion is an important textual feature in the legal text. It connects the syntactic grammar and the lexicons into together closely. However, the choice of cohesive devices are not so diversified in such legal text, which reflect the elites, formality, compulsion, rigidness, and accuracy of the Law. Thus it achieves the authoritativeness of the Law, Criminal Procedure Law of the People's Republic of China.

Cohesion is not the form of structure but a kind of semantic relationship, which uses devices such as reference, ellipsis, substitution, conjunction and collocation to connect each component which is structurally unrelated but semantically interdependent together. Therefore, to study cohesion of the legal text can help us better grasp the stylistic characteristics conveyed by the Law.

Studies on textual cohesion in a legal text are still in the course of development, which foreshadows a lot of possible areas for linguistic scientists to work in. This potentially valuable subject will draw more attention and there is a great deal to do in this respect.

\section{REFERENCES}

[1] Criminal Procedure Law of the People's Republic of China (the Chinese version and the English version). (2018). Available at: https://www.lawinfochina.com/display.aspx?id=29202\&lib=law

[2] Fakuade, G.\& Vargs, J. L. (1992). Cohesion and text creation. Language Learning Journal, 5(1), 88-89

[3] Georgakopoulou, A and Dionysis. (1997). Discourse Analysis. Bodmin; Cornwell: Edinburgh University Press.

[4] Halliday, M.A.K. (1994). Introduction to Functional Grammar (2nd edn). London: Edward Arnold.

[5] Halliday, M.A.K. and Hansan, R. (1976). Cohesion in English. London: Longman Group Limited. 2, 284.

[6] Halliday, M.A.K. \& C.M.E.M. Matthiessen. (2004). Introduction to Functional Grammar ( $3^{\text {rd }}$ edn). London: Edward Arnold.

[7] Hasan, R. (1984). Coherence and Cohesive Harmony. International Reading Association.

[8] Maley, Y. (1994). The language of the law. In Gibbons, John. (Ed.), Language and the law. London: Longman. 3-50.

[9] Shifang Li \& Yifan Wang. (2020). Systemic Functional Analysis of Thematic Structure in Legislative Discourse-Based on Criminal Procedure Law of the People's Republic of China. Proceedings of the 2020 International Conference on Language, Communication and Culture Studies (ICLCCS 2020). Atlantis Press.

[10] Shifang Li \& Yifan Wang. (2021). An Analysis of the Textual Features of Legal Discourse from the Perspective of Thematic Progression: Based on Criminal Procedure Law of the People's Republic of China, Theory and Practice in Language Studies. (11) $7,829-835$. 
[11] Thompson, Geoffrey. (2004). Introducing Functional Grammar (2nd edn). London: Edward Arnold. 179,180.

[12] Zhu yongsheng. (2001). The contribution of functional linguistics to stylistic analysis. Foreign languages and foreign language teaching. (5), 1-4.

Shifang Li was born in Harbin, China in 1967. She received her PH. D degree in English Language and Literature from Northeast Normal University, China in 2008.

She is currently a professor in the School of Languages and Cultures, Shanghai University of Political Science and Law, Shanghai, China. Her research interests include Forensic Linguistics, text analysis and Pragmatics Linguistics.

$\mathrm{Dr}$. $\mathrm{Li}$ is an executive director, deputy secretary general, of the Legal Linguistics Committee of China.

Yifan Wang was born in Harbin, China in 1995. She received her bachelor degree of laws in School of Law, Daqing Normal University, China in 2018.

Yifan Wang is a Legal and Compliance Specialist of the Legal Department at Shanghai Elearning Investment Consulting Co., Ltd. 